\title{
La Reforma y los bienes de la Iglesia en Chiapas: su desamortización y nacionalización, 1857-1867*
}

Antonio Padilla

$E_{1}$ propósito de este artículo es describir el proceso de desamortización y nacionalización de los bienes de la Iglesia en el estado de Chiapas. Ese proceso se inició en época relativamente temprana. La desamortización se promovió desde la segunda década del siglo pasado, al promulgarse la primera ley agraria del estado, en 1826 , a la vez que las peticiones y reclamos de los eclesiásticos, tanto seculares como regulares.

La Ley Lerdo, junio de 1856, y la Ley de Nacionalización de los Bienes Eclesiásticos, julio de 1859 , reforzaron esa tendencia y favorecieron las aspiraciones de un grupo de propietarios, quienes habían adquirido gran parte de esos bienes. Las autoridades religiosas solicitaron a diversas autoridades federales y estatales la devolución de sus propiedades, argumentando sobre todo extrema pobreza. Los tonos y matices empleados fueron marcados por las diferentes corporaciones que existieron en la entidad. Aunque nunca obtuvieron respuesta favorable, el afán de conseguir su objetivo no disminuyó.

Es conveniente aclarar que el trabajo no profundiza en el análisis de la situación política en la cual se desarrolló la venta de los bienes eclesiásticos, debido a la escasa información localizada que impidió formar un marco adecuado a las disputas entre las autoridades religiosas y las autoridades locales chiapanecas durante el periodo de la Reforma.

Dicha limitación requiere explicar las fuentes consultadas y las particularidades del artículo. En el Archivo General de la Nación se encontraron varios documentos que aclaran y detallan la situación de la Iglesia en Chiapas. El fondo de Justicia Eclesiástico es particularmente rico en la descripción de los bienes de la Iglesia en vísperas del movimiento reformista. También se consultaron los manuscritos del fondo de Bienes Nacionalizados en el cual se localizaron varias "Noticias y estados" de los bienes y ventas eclesiásticos.

En la biblioteca Manuel Orozco y Berra se situaron varias memorias de los gobernadores, pero no hubo referencias específicas al proceso de desamortización y nacionalización de los bienes de la Iglesia.

Así, el artículo constituye un primer acercamiento al estudio y análisis de los bienes y ventas de las posesiones de la Iglesia en Chiapas.

Evaluar volumen y valor de los bienes eclesiásticos en el estado de Chiapas es una labor compleja y difícil pues existe poca información sobre el tema. El obispo de la diócesis de Chiapas, Carlos María Colina

\footnotetext{
* Este trabajo fue resultado del seminario de "La Reforma", impartido en el Centro de Estudios Históricos de El Colegio de México. Dicho seminario fue dirigido por el doctor Jan Bazant, a quien agradezco sus comentarios y sugerencias.
} 
y Rubio, expuso en varias ocasiones la situación de pobreza del clero chiapaneco y las dificultades que representaba para hacer efectiva su labor espiritual. Según el obispo, era tal la pobreza que "mandé cerrar la iglesia catedral por no tener ya ni aun con que sufragar el insignificante gasto de una misa cantada"."

Algunos historiadores contemporáneos han señalado que, en vísperas de la guerra de Reforma, "los latifundios de la Iglesia representaban entonces el $30 \%$ de la superficie acaparada". 2

Es posible que esta aseveración haya sido excesiva, pues aun suponiendo que la información proporcionada por las autoridades eclesiásticas ocultara la situación real de los bienes de la Iglesia, el cotejo de varias fuentes permite presuponer que las estimaciones del obispo Colina y Rubio eran adecuadas. Varios viajeros han descrito las condiciones económicas y sociales del estado a mediados del siglo XIX y han coincidido en destacar la pobreza de Chiapas. La Iglesia no era la excepción. ${ }^{3}$

Los datos más remotos sobre las propiedades eclesiásticas son los que proporciona fray Juan Manuel García de Bargas y Rivera. En una visita general a la diócesis chiapaneca realizada en 1774 , informó que la principal orden mendicante, los dominicos, poseía 14 haciendas: Éstas se encontraban distribuidas en los valles templados de Ciudad Real (actualmente San Cristóbal de Las Casas), Teopisca y Comitán. ${ }^{4}$

Lamentablemente, el autor no registró los productos anuales de las haciendas, por lo que resulta imposible conocer el valor aproximado de cada una de ellas.

El obispo de Chiapas, Colina y Rubio, realizó en 1856 una visita pastoral por su diócesis que sirvió de base para elaborar un informe (el cual envió al ministro de Justicia y Negocios Eclesiásticos) sobre la situación de los bienes de la Iglesia. ${ }^{5}$

Este informe, redactado en febrero de 1856 , tal vez haya sido el documento más completo y revelador sobre las propiedades de la Iglesia en Chiapas. En él, Colina y Rubio destacó la existencia de 60 templos e iglesias parroquiales, así como 60 o 70 ermitas en diversos pueblos, "hechos de hoja o sacate sin que en general dichas iglesias o capillas [tengan] fondo alguno para subsistir. Respecto de cofradías no hay alguna en toda mi diócesis que merezca este nombre". Las que poseía apenas alcanzaban capitales de $60,80,100$ o 110 pesos. Los capitales piadosos (capellanías), impuestos sobre fincas rústicas y urbanas, sumaban 177 , cuyos capitales eran de 300 a 500 pesos "y muy raras veces tres o cuatro mil pesos". ${ }^{6}$

Colina y Rubio agregaba que más de la mitad de ellas no estaban al corriente de sus réditos "por atrasos o falta de voluntad de los que reconocen para pagarlo". Sobre hienes inmuebles señalaba que contaba con una finca de campo, teniendo un valor aproximado de $\$ 6000$

\footnotetext{
'Archivo General de la Nación, Justicia Eclesiástico (en adelante AGN-JE), t. 167, f. 408-411.

${ }^{2}$ Henri Favre, Cambio y continuidad entre los mayas de México, México, Siglo XXI, 1973 , p. 55.

${ }^{3}$ Margo Glantz, Viajes en México. Crónicas extranjeras, México, Sep/80, 1982 , p. 368-451; Antonio García de León, Resistencia y utopía, México, Era, 1985, t. I.

${ }^{4}$ García de Bargas citado en García de León, op. cit., t. I, p. 112.

${ }^{5}$ AGN-JE, t. 167, f. 289-293.

${ }^{6}$ Para establecer el monto aproximado de capitales de cofradias tomamos como promedio $\$ 110.00$ que multiplicamos por 200 , números establecidos por el obispo, lo cual da por resultado $\$ 22000.00$.
} 
y unos terrenos de la fábrica de la parroquia de Tonalá "y cuatro o seis fincas urbanas".

En relación con los aranceles por servicios eclesiásticos no existían debido a que habían sido sustituidos por "cuadrantes" que eran diversos "según los mismos lugares donde se observan". La congrua, sustentación de los párrocos, se estableció mediante "doctrinas de indios". El cálculo de éstas fue de 200 "que no pueden producir con todo y funciones, ni aun la suma de $\$ 2000.00 "$ ".

En su informe, el obispo Colina y Rubio se quejaba por la falta de puntualidad en la entrega de su asignación de $\$ 6000$ anuales que habian dispuesto las autoridades civiles desde 1840 para el sostenimiento del culto religioso.

Sobre el rubro de conventos indicaba el perteneciente a las religiosas de La Encarnación, en donde residían 8 monjas, 6 criadas y 3 niñas, "sin más rentas que las cortas pero seguras de varios capitales que tienen impuesto a réditos de un $5 \%$ anual sobre diversas fincas de la diócesis y cuyos productos exceden en muy poco $\$ 2000$ pesos anuales".

Cabe aclarar que el obispo omitió registrar los conventos de dominicos, así como el número de fincas rústicas y urbanas que éstos poseían, tal vez porque eran propiedad del clero regular. ${ }^{7}$

En otros documentos se ponen de manifiesto los problemas que enfrentaban las corporaciones religiosas para cumplir con su misión espiritual, así como para sustentarse. En una carta enviada a su "Alteza Serenísima", fechada el 23 de febrero de 1855, el obispo Colina y Rubio protestó por la aplicación del impuesto de captación, aduciendo que la Iglesia de Chiapas era la única en todo el país que había sido obligada a pagar esa contribución, "con mengua del honor y decoro de su ministerio". Terminaba su misiva reiterando que había sido "un insulto a la pobreza que tal vez más que en cualquiera otra Diócesis tienen aquellos ministros del Altar". ${ }^{8}$

Bajo la presidencia de Ignacio Comonfort, el obispo manifestó "acatar y respetar a toda la autoridad constituida" y solicitaba "la protección del supremo gobierno para subvenir así a las continuas necesidades de muy pobre, muy escasa y desprovista Iglesia". Además recordaba que la asignación que le había sido otorgada no se había cumplido desde el año anterior y urgía para que le fuese entregada su anualidad, pues "siendo tal la necesidad de esta Iglesia que aun el costo de la cera y vino para las funciones del culto de este año no lo ha podido sufragar sus cortas y muy escasas ventas". 9

En 1854, dominicos y franciscanos, pertenecientes a la provincia de Predicadores de San José de Chiapas, enviaron varias representaciones al Ministerio de Justicia y Negocios Eclesiásticos en las que solicitaban se les eximiera del pago de gavelas por sus fincas o la introducción de frutas, ya que éstas casi "han quedado en el estado de desmembración de sus terrenos reducidos a dominio particular, lo que con la prohibición de nuevas adquisiciones no es extraño que haya conducido al Convento al estado de miseria". ${ }^{10}$

\footnotetext{
${ }^{7}$ Para el cálculo sobre capitales piadosos se siguió el mismo procedimiento explicado en la nota 6 . En este caso, el promedio fue de $\$ 400.00$ que multiplicados por las 177 capellanias dieron un capital de $\$ 70800.00$.

${ }^{8}$ AGN-JE, t. 167, f. 289-293.

${ }^{9} \mathrm{AGN}-J E$, t. 170, f. 539-540.

${ }^{10}$ AGN-JE, t. 164, f. 478.
} 
Agregaban que el convento de franciscanos sólo se sostenía "con las lismosnas espontáneas", deduciendo los inquilinos réditos y "el impuesto sobre los efectos nacionales y nacionalistas que se introducen para su consumo se le corte el arbitrio que tienen para su subsistencia". De nueva cuenta pusieron de manifiesto que "no son comparables, ni podrán nivelarse los miserables conventos de Chiapas con el resto de la República".

En lo que respecta a aranceles y derechos parroquiales la situación no era menos halagadora. En el primer rubro, los ingresos eran bajos, en gran medida porque la mayoría de la población era indígena. En el caso de los diezmos, éstos habían disminuido debido a la sustracción de la "caridad cristiana".11

En un documento, que al parecer es continuación del borrador de la Memoria de justicia de 1856, se expone el "estado general de los productos del diezmo en todas las diócesis de la República", correspondiente al quinquenio 1851-1855. En el obispado de Chiapas, la recaudación fue de $\$ 9000.00$; comparada con los ingresos de Oaxaca por ese concepto, que fueron de $\$ 111163.00$ y los de Nuevo León de $\$ 16162.00$, se hace notoria la desproporción que recibían esos obispados para el quinquenio. ${ }^{12}$

Las fuentes publicadas por el gobierno central proporcionan alguna información sobre las propiedades eclesiásticas en Chiapas.

En la Memoria de justicia y negocios eclesiásticos de 1884 se presentaron las fincas rústicas y urbanas de cada estado de la república. Según la fuente, la orden de los dominicos poseía 25 fincas con valor aproximado de $\$ 262140.00$ y con productos de $\$ 13107$; además tenían dos fincas urbanas con valor de $\$ 800.00$.

En el borrador de la memoria de 1856 se asienta que las fincas rústicas eran 15 , valuadas en $\$ 119990.00$, así como también siete fincas urbanas por valor de $\$ 18960.00$. Es decir, que en un lapso de 12 años el valor de las propiedades dominicas había disminuido $47 \% .^{13}$

En esa memoria se anotó que la finca, propiedad del convento de religiosas de La Encarnación, tenía un valor de \$58 870.00 .

Esta era la situación de los bienes del clero en Chiapas, próximo el movimiento de Reforma y que quizá pueda sintetizarse en una palabra: pobreza. ${ }^{14}$

Si apreciár los bienes de la Iglesia resultó una tarea compleja, no menos fue el estimar el impacto de los procesos de desamortización y nacionalización en el estado. Expedida la primera ley agraria de Chiapas, en 1826, después de haberse independizado de la corona española, se puso en marcha el empeño desamortizador. Uno de los propósitos de esa ley fue "sacar a la agricultura del abandono en que actualmente se halla, y darle impulso que al paso que ceda en beneficio de sus comitentes refluya también en el del estado". ${ }^{15}$

En uno de sus artículos se señalaba que las tierras adquiridas no podian ser traspasadas a manos muertas bajo ningún título. En la práctica se impedía al clero, tanto regular como secular, beneficiarse de

11 AGN-JE, t. 167, f. 201.

${ }^{12}$ AGN-JE, t. 164 , f. 478.

${ }^{13}$ AGN-JE, t. 167, f. 201.

${ }^{14}$ La suma total de los bienes de la Iglesia, al iniciarse el movimiento de Reforma, ascendía en cálculos aproximados a $\$ 228620.00$.

${ }^{15}$ AGN-JE, t. 147, Ley Agraria de 1826 (manuscrita). 
esa disposición y, lo que era más grave, las propiedades eclesiásticas podían ser denunciadas como baldías o consideradas como terrenos nacionales. Posteriormente se promulgaron otras disposiciones agrarias que recuperaban o se apoyaban en el espíritu de la de 1826. En 1844 y 1847 se publicaron nuevos ordenamientos agrarios, agregándose la fijación de medidas para pueblos y ejidos, en un acto que ha sido considerado por algunos historiadores un freno al despojo que sufrían los pueblos indígenas del estado. ${ }^{16}$

Aunque las posesiones de comunidades y pueblos fueron denunciadas preferentemente como baldías, las propiedades de las corporaciones religiosas fueron preferidas para su denuncia por los antiguos arrendatarios. La desamortización fue tan acelerada que unos años antes del inicio de la Reforma las autoridades eclesiásticas solicitaron la devolución de sus fincas y terrenos. Quizá ello explique la insistencia en sus peticiones; sin embargo, los largos años en litigio y los extensos alegatos presentados por esas corporaciones no fueron suficientes para convencer a las autoridades civiles.

Instalado el gobierno conservador de Antonio López de Santa Anna en 1853, el cabildo eclesiástico de la diócesis' chiapaneca solicitó la restitución de varias haciendas que habían pertenecido a la iglesia catedral. En dicha solicitud se exponía la "triste situación de esta iglesia y el obispado", así como varias causas que explicaban esa situación. Dentro de los motivos indicados estaba la aplicación de las leyes agrarias que, en opinión del cabildo, había favorecido sólo a un grupo de propietarios particulares. ${ }^{17}$ Según explicaba la petición, el arrendamiento de la hacienda producía lo indispensable para mantener dos curatos y al obispo. La pobreza del obispo también reflejaba la de los feligreses, quienes tenían estancias y fincas insignificantes que "no provocan las miradas de un propietario de consideración". Esas fincas contribuían al sostenimiento de los curas.

El alegato principal se centraba en que "sean cuales fueran las instituciones generales de la Nación, se ha llevado al caso sin respetar la posesión de una centuria de años". El cabildo concluyó que el daño más grave era el que padecían los indígenas, a quienes se despojaba de sus pocos bienes, los cuales servían para el pago de las obvenciones parroquiales habiendo provocado una situación desesperada:

de que las dispersiones de los mismos indígenas en busca de su subsistencia, desamparando sus lugares; de aquí la sorda esclavitud de estos pobres sometiéndose al servicio de aquel mismo que posee los terrenos que cultivará tal vez por un mezquino salario. ${ }^{18}$

El escrito terminaba profetizando que si no se daba una solución adecuada a los despojos que venían sufriendo los indígenas se produciría una "guerra de castas". El ayuntamiento eclesiástico no se equivocó en este punto: en 1869 se rebelaron los indígenas pero no sólo contra el despojo de sus propiedades sino contra las contribuciones de los curas. ${ }^{19}$

${ }^{16}$ AGN-JE, t. 147, Leyes Agrarias de 1844 y 1847 (manuscritas). Dos autores que sostienen la opinión del despojo violento y aun extralegal de las propiedades indígenas son García de León y Trens.

${ }^{17}$ Leyes Agrarias del estado de Chiapas en 1844 y 1847.

${ }^{18}$ AGN-JE, t. 167, f. 436-442.

${ }^{19}$ Favre, op. cit., p. 301 y ss. 
La Sala Capitular de la Catedral envió una nueva exposición en la que expuso el proceso de "despojo" de la hacienda San Nicolás y Solyatengo, que aparecería reiteradamente en las denuncias contra los bienes de la Iglesia, una de las propiedades más ricas y productivas del estado de Chiapas, así como de terrenos pertenecientes a varias cofradías. ${ }^{20}$

El Consejo de Estado notificó su resolución al cabildo eclesiástico. En ella admitía la penuria que afrontaba el obispado pero resolvió que la solicitud de devolución de las haciendas y terrenos de cofradías era improcedente. Esa institución consideró como "acto consumado" la translación de los bienes eclesiásticos a dominio de particulares:

Por el expediente existente aparecen que estas leyes han sido dadas no sólo en tiempo de la Federación sino bajo todos los gobiernos desde el año de 1826 hasta el de 1849; y por las diligencias, que la adjudicación de los terrenos se hizo conforme a dichas leyes con intervención de los tribunales, audiencias y aun apariencia de consentimiento que representaban a los interesados de manera que este es un acto consumado y en que intervino la autoridad judicial. ${ }^{21}$

Así, el supremo gobierno de la nación se descargó de cualquier responsabilidad aduciendo que no debía intervenir en el asunto. No correspondía a éste enmendar los posibles errores de procedimiento que, según el cabildo, se habían cometido en el proceso de denuncia y enajenación "sino a los tribunales del estado".

Las disputas entre propietarios y clero se habían producido durante la aplicación de las leyes agrarias. En 1849 , los dominicos solicitaron al Congreso estatal la restitución de varias haciendas, contando con el apoyo del gobernador Ramón L. Larráinzar. En esa ocasión la defensa de los intereses de los propietarios fue realizada por Ángel Albino Corzo, quien más tarde ocuparía la gubernatura estatal, entre los años de 1855 a 1866 , y encabezaría la fracción liberal chiapaneca. ${ }^{22}$

En la defensa argumentó la necesidad de dar seguridad a los terrenos y posesiones de los particulares y explicó que el proyecto patrocinado por el gobernador Larráinzar intentaba "falsear el legítimo derecho adquirido por compras hechas a los gobiernos del estado según sus leyes agrarias". ${ }^{23}$ Corzo aclaró que el recurso de los dominicos, en caso de haberse aceptado, "hubiese puesto en altos compromisos a los propietarios de Chiapa, Comitán y Ocosingo". ${ }^{24}$

No le faltaba razón al prominente liberal. Varias familias, entre ellas la suya, habían aprovechado las leyes de desamortización para hacer crecer sus propiedades a grandes extensiones. ${ }^{25}$ Trens sitúa a las familias que se beneficiaron mediante las disposiciones agrarias dentro del bloque liberal y al grupo de defensores de las propiedades eclesiásticas:

${ }^{20}$ AGN-JE, t. 167, f. 508-511.

${ }^{21}$ AGN-JE, t. 183, f. 514-517.

${ }^{22}$ Ángel Albino Corzo, Segunda reseña de sucesos acaecidos en Chiapas desde 1847 hasta 1867, Chiapas, Imprenta del Estado, 1868, p. 24; Octavio Gordillo y Ortiz, Diccionario biográfico de Chiapas, México, Costa Amic, 1977, p. 46.

${ }^{23}$ Corzo, op. cit., p. 26.

${ }^{24}$ Ibid., p. 28.

${ }^{25}$ Favre, op. cit., p. 55. 
Corzo, Castellanos, Solórzano, Ruiz, Molina y otros liberales de abolengo fueron el ariete que el destino deparó para cuartear hasta sus cimientos la resistencia que oponian los Cardona, los Larráinzar, los Quesada, los Piñeiro que a orgulllo tenían empuñar el marchito gonfalóan que de lábaro servía a los intereses clericales y retrógrados de Chiapas. ${ }^{26}$

El 13 de agosto de 1859, el gobernador Ángel Albino Corzo promulgó y puso en vigor la Ley de Nacionalización de los Bienes Eclesiásticos. En los dias subsecuentes se publicaron las restantes Leyes de Reforma. ${ }^{27}$ La fracción que se había beneficiado por las leyes agrarias se fortaleció aún más con esa disposición como usufructuaria principal. ${ }^{28}$

Las noticias suministran información básica sobre la venta de los bienes, en las cuales se registraban nombre de las propiedades, su ubicación, nombre del adjudicatario, precio y corporación a la que pertenecían. Los datos más antiguos localizados se refieren a las transacciones del año de 1860 . El número de contratos fue de 14 adjudicaciones por un monto de $\$ 30531.00 .^{29}$

En relación con otros estados es notoria la desigualdad tanto en el número de convenios como en el monto de las operaciones. Por ejemplo, en el estado de Puebla, "las operaciones de venta en 1861 fueron muy cuantiosas: desde el 7 de enero hasta el 31 de marzo de 1861, en la ciudad de Puebla se rescataron bienes eclesiásticos por $\$ 3077387.00 .^{30}$

De 1862 a 1863 se produjeron 35 adjudicaciones con valor de $\$ 38554.64$. Estos dos años fueron los últimos en que se registraron "operaciones de adjudicación de terrenos o fincas". ${ }^{31}$

Los años que van desde 1864 hasta 1867 se caracterizaron por compromisos de redención de capitales por la cantidad de $\$ 7392.00$. En este caso, conviene señalar que la presentación de la información alude a fincas hipotecadas y corporación a que pertenecían. Esta situación puede provocar algunas confusiones pues muchas de esas propiedades aunque estaban hipotecadas no necesariamente pertenecían a una corporación religiosa, y sí, en cambio, la hipoteca pudo haber pasado a manos del estado que fijó un monto para su liquidación. ${ }^{32}$

Sobre capitales de capellanias y redenciones de capital se localizaron sólo datos para 1861. En el primer caso, se habían reconocido capitales por la cantidad de $\$ 55764.00$, mientras que por denuncia de capitales el monto ascendió a $\$ 19689.97 .{ }^{33}$ La suma de los diferentes

${ }^{26}$ Manuel R. Trens, Historia de Chiapas, México, s.e., 1942, p. 461.

${ }^{27}$ Trens, op. cit., 1957, p. 584.

${ }^{28}$ A rchivo General de la Nación, Bienes Nacionales (en adelante AGN-BN), "Jefatura de Hacienda remite relación de expedientes de bienes nacionalizados". Las noticias de la Jefatura Superior de Hacienda proporcionan una idea del proceso de venta de los bienes eclesiásticos.

${ }^{29}$ AGN-BN.

${ }^{30} \mathrm{Jan}$ Bazant, Los bienes de la Iglesia en México, México, El Colegio de México, 1984, p. 243.

${ }^{31}$ AGN-BN, "Estados descriptivos de las fincas desamortizadas".

${ }^{32}$ El titular de la Jefatura aclaró que "con motivo del destrozo que sufrió el archivo de esa Jefatura en el año de $\mathbf{1 8 6 3}$ al ser incendiado y saqueado no ha podido ser posible presentar una obra perfecta".

${ }^{33} \mathrm{AGN}-\mathrm{BN}$, "Estado que ministra la noticia de sumas procedentes de las redenciones de capitales y bienes que fueron nacionalizados al clero", y "Noticia que manifiesta lo practicado en esta oficina respectivamente a capitales". 
tipos de contratos y el valor de las operaciones hasta 1867 , sin contabilizar las posibles denuncias de capital y capellanias en los siguientes años, ascendió a $\$ 184453.39$. El número de contratos y el valor de las operaciones refleja la situación de los bienes de la Iglesia y hace coincidir las afirmaciones del obispo Colina y Rubio sobre el estado de la diócesis chiapaneca. Esta afirmación no niega que haya habido beneficiarios de las leyes de desamortización y nacionalización.

La fracción de propietarios privados que había visto crecer sus fincas, al amparo de las leyes agrarias, fue impulsada a proseguir el proceso de acumulación de tierras, haciendo cumplir, en gran medida, los objetivos de la reforma liberal, entre los cuales se encontraba la creación de propietarios privados. Es cierto, éstos no eran pequeños propietarios, como pretendieron los promotores de las leyes desamortizadoras, pero cumplieron los propósitos políticos, es decir, se constituyeron en apoyo al régimen liberal. Esa fracción respaldó las tesis liberales y brindó su apoyo incondicional a la República, contribuyendo a la estabilidad del régimen en gran parte del sureste del país.

Las Noticias ofrecen una idea preliminar de las personas y grupos favorecidos en especial por la Ley de Nacionalización de los Bienes Eclesiásticos.

Los personajes y actores que ocuparon puestos en las distintas administraciones de Corzo, ya como diputados en el Congreso del Estado o bien como funcionarios públicos, aparecen como adjudicatarios en las listas enviadas por la Jefatura de Hacienda.

En la región de Comitán destacan Isidoro Castellanos, Matías Castellanos, José Ponciano Solórzano, Nicolás Ruiz y Pantaleón Domínguez, futuro gobernador en los primeros años del régimen porfirista.

En la región de Chiapa y Tuxtla están José Domingo Chanona, Gregorio Cristiani, Casimiro Cristiani, Jesús Esponda, José Gabriel Esquinca, Juan Clímaco Corzo y Benigno Calimayor.

El 13 de octubre de 1855, el gobernador del estado, Fernando Nicolás Maldonado, envió una circular a los prefectos en la cual les informaba sobre la situación política que vivían el país y Chiapas. En esa circular expresó su intención de renunciar a la gubernatura, así como la situación de la administración estatal. ${ }^{34}$

Dicha comunicación fue una respuesta a los ataques que había recibido del ayuntamiento de San Cristóbal, el cual lo acusaba de haber sido agente "de la administración desacertada del general Arista, ya como esbirro del tirano Santa Anna". ${ }^{35}$

Días antes el ayuntamiento de Chiapa, cuna de Ángel Albino Corzo, había proclamado su adhesión al Plan de Ayutla y llamó a sus similares a pronunciarse en ese sentido. El 20 de octubre, Maldonado renunció y entregó el puesto a Corzo. ${ }^{36}$

Éste dirigió un manifiesto a los chiapanecos informándoles que asumía la gubernatura del estado en forma provisional "para evitar a todo trance la anarquía". Fue nombrado un Consejo de Gobierno que debía ocuparse de la elaboración del Estatuto Orgánico Provisional del Estado. Este Consejo quedó integrado entre otros, por José Gabriel Esquinca, Matías Castellanos y Nicolás Ruiz.

${ }^{34}$ Biblioteca Manuel Orozco y Berra del Instituto Nacional de Antropología e Historia (en adelante вмов), Archivo de Chiapas, t. vi, doc. 75.

${ }^{35}$ вмов, Archivo de Chiapas, t. vi, doc. 77.

${ }^{36}$ вмов, Archivo de Chiapas, t. vl, doc. 78. 
Meses después, Corzo solicitó licencia al Congreso estatal y fue sustituido por Domingo Ruiz Molina. ${ }^{37}$ Estos hechos marcan el ascenso al poder de la fracción liberal y las recurrentes peticiones de licencia de Corzo.

En julio de 1856, el gobernador sustituto enfrentó una rebelión dirigida por el ex diputado Juan Ortega, quien explicó que su levantamiento se debía a la ilegitimidad del gobierno presidido por Corzo y reconocía su adhesión a la Federación. ${ }^{38}$

Según Trens, el movimiento sirvió a Ortega y socios "para ensangrentar los campos de Chiapas y para despertar en el clerecía y en los ultramontanos las esperanzas de restaurar un régimen económico y despótico que pugnaba por el atraso, el oscurantismo, las preminencias y la conservación de las riquezas del clero". ${ }^{39}$

Con motivo de la expedición de la Ley Lerdo, que coincidió con el levantamiento de Ortega, el obispo Carlos María Colina y Rubio dio a conocer una pastoral en la que protestaba por las disposiciones de la ley. En su carta expuso que:

Los prelados de la Iglesia ... no somos árbitros, no somos dueños o señores, sino meros administradores de los bienes eclesiásticos que están a nuestro cargo y, en calidad de tales, no podemos consentir en su absoluta enajenación, tal como lo previene la ley del 25 de junio. ${ }^{40}$

La respuesta del gobierno estatal fue prohibir la circulación de la pastoral. Otro motivo de fricción fue la negativa del obispo a oficiar y recibir al Congreso del Estado en misa solemne después de haber jurado la Constitución de 1857.

El gobernador Corzo le envió una misiva en la cual le informaba su preocupación por la actitud asumida. Según explicó Corzo, esa conducta era una respuesta "porque llegó el día de la patria en que no fuese esa clase la que dispusiese de la suerte de los pueblos". ${ }^{41}$

El incidente concluyó al imponérsele una multa al obispo Colina y Rubio de $\$ 300.00$, los cuales ingresarían a la Tesorería del Estado.

No faltó la protesta del obispo por la intervención de los bienes de la Iglesia a consecuencia de la insurrección de Zacapoaxtla. ${ }^{42}$ En su quinta pastoral señaló que la confiscación de los bienes eclesiásticos era una intromisión en "la independencia, libertad y soberanía de la Santa Iglesia en todo lo que le corresponde". ${ }^{43}$

En abril de 1857 , el obispo Colina y Rubio envió una larga y detallada exposición al ministro de Justicia, en que protestaba por la ley que regulaba los derechos y obvenciones parroquiales. El argumento central de la representación fue que esa disposición significaba una intromisión de la autoridad civil en asuntos que eran competencia exclusiva de la autoridad eclesiástica, además de que pretendía acabar con los medios de sustentación de "los ministros de la religión". ${ }^{44}$

${ }^{37}$ Trens, op. cit., 1957, p. 516.

${ }^{38}$ BMOB, Archivo de Chiapas, t. vi, doc. 25.

${ }^{39}$ Trens, op. cit., 1942, p. 497.

${ }^{40}$ Carlos María Colina y Rubio, Séptima carta pastoral, Guatemala, Imprenta la Paz, 1856.

4 ' BMOB, Archivo de Chiapas, t. vir.

${ }^{42}$ Jan Bazant, Antonio Haro y Tamariz y sus aventuras políticas, 1811-1869, México, El Colegio de México, 1985.

${ }^{43}$ Carlos María Colina y Rubio, Quinta carta pastoral, México, Imprenta de Chiapas, 1856.

44 AGN-JE, t. 170 , f. $485-491$. 
El 13 de agosto de 1859 se promulgaron las Leyes de Reforma en el estado. La respuesta de dominicos y franciscanos fue el abandono de sus conventos y su traslado a Guatemala. El obispo calificó esas leyes de "írritas, heréticas y disolventes". ${ }^{45}$

En septiembre de ese año, Corzo ordenó la expulsión del obispo Colina y Rubio junto a la de varios presbíteros. Ésa fue la última ocasión en que las autoridades eclesiásticas elevaron su protesta ante el ejecutivo estatal. 